\title{
Vulvar intraepithelial neoplasia and vulvar squamous cell carcinoma: a clinicopathologic study of 18 cases
}

\author{
Ebru Demiralay ${ }^{1 \star}$, Nihan Haberal Reyhan ${ }^{1}$, Özlem Özen ${ }^{1}$, Burcu Ksa ${ }^{2}$, Ali Ayhan ${ }^{2}$ and Beyhan Demirhan ${ }^{1}$ \\ Correspondence: ebrudemiralay@yahoo.co.uk \\ ${ }^{1}$ Department of Pathology, ${ }^{2}$ Department of Obstetrics and Gynecology, Faculty of Medicine, Baskent Universty, Ankara, Turkey.
}

\begin{abstract}
Background: The vulvar intraepithelial neoplasia is divided into two groups: usual type and differentiated type. The differentiated vulvar intraepithelial neoplasia which is frequently seen together with the invasive squamous cell carcinoma can be confused with some benign lesions. To analyse p16, p53, and Ki-67 expression characteristics of different histological types of invasive squamous cell carcinoma of the vulva and vulvar intraepithelial neoplasia is aimed in this study.
\end{abstract}

Methods: In this study, immunohistochemical analysis of 18 vulvectomy cases with p16, p53, and Ki-67 was performed.

Results: Of 18 patient who underwent vulvectomy, 9 had invasive squamous cell carcinoma and 9 vulvar intraepithelial neoplasia. 3 additional vulvar intraepithelial neoplasia lesions were found accompanying the invasive squamous cell carcinomas. Mean Ki-67 PI was 32,3\% in usual type (human papilloma virus-related) vulvar intraepithelial neoplasia cases (n:9), and 26,4\% in differentiated vulvar intraepithelial neoplasia cases (n:3)(p>0,05). Mean p16 staining degree was 2,6 for usual type vulvar intraepithelial neoplasias. No p53 expression was present in squamous cell hyperplasia or lichen sclerosis lesions.

Conclusions: Ki-67 PI does not have significant value in recognizing vulvar intraepithelial neoplasia usual type and differentiated vulvar intraepithelial neoplasia. p53 positivity can be of value in distinguishing especially differentiated type vulvar intraepithelial neoplasia from benign lesions.

Keywords: vulva, vulvar intraepithelial neoplasia, invasive squamous cell carcinoma

\section{Background}

Based on histological observations, approximately $90 \%$ of all primary malign carcinomas of the vulvar tumors are invasive squamous cell carcinoma (ISCC) [1,2]. According to the currently popular classification system, vulvar invasive squamous cell carcinoma (ISCCV) is divided into 3 main histological groups; basaloid, warty and keratinizing ('conventional' or 'typical' keratinizing) types $[\mathbf{1}, \mathbf{3}, \mathbf{4}]$. Conventional type is the most common histological type of ISCCVs. Basaloid and warty types of ISCCV are thought to originate from basaloid and warty type vulvar intraepithelial neoplasia (VIN). This type of VINs has strongly been associated with human papilloma virus (HPV) [4]. VIN terminology was modified in 2004 by The International Society for the Study of Vulvovaginal Disease (ISSVD), and was mainly divided into two groups: VIN usual type and VIN differentiated (simplex) type. These terms account for VIN 2 and VIN 3 in the older terminology, and the term VIN 1 has not been used anymore [5,6-8].
ISCCVs are grouped into two general types according to their different clinicopathologic features. The first group is the type seen in young age groups (35-65 years old) and is associated with HPV, and the second group is the type seen mostly in older women (55-85 years old), is unrelated to HPV, and has different etiological factors $[\mathbf{1 , 2 , 9 ]}$.

The type related to HPV accounts for $1 / 3$ of all ISCCVs. The group named as classic VIN, whether warty or basaloid is characterized by accompanying highly differentiated VIN and high $\mathrm{Ki}-67$ proliferation index (Ki-67 PI). In addition, there is increase in the risk of squamous neoplasia, particularly of cervix and other parts of lower genital tract. The patients in this group appear to have a better prognosis than the group of patients with ISCC unrelated to HPV $[1,2,9]$.

The second group (unrelated to HPV) accounts for $2 / 3$ of all ISCCs. The patients in this group typically develop a conventional (keratinizing) type ISCC associated with lichen sclerosis (LS) and squamous hyperplasia ( $\mathrm{SCH})$, and recent

(c) 2012 Demiralay et al; licensee Herbert Publications Ltd. This is an open access article distributed under the terms of Creative Commons Attribution License (http://creativecommons.org/licenses/by/3.0), This permits unrestricted use, distribution, and reproduction in any medium, provided the original work is properly cited. 
studies have shown the relationship with differentiated (simplex) VIN. Moreover, mutation in p53 tumor suppressing gene has often been observed [1,2,10,11].

The differentiated VIN often observed together with the second group accounts for 2- $10 \%$ of all VINs [12]. These lesions have often been left unnoticed because histological criteria for differentiated VIN have not been clearly described and because there have been only a few cases in literature.

The aim of this study was to study 8 ISCC, one verrucous carcinoma and 9 VIN cases diagnosed at Baskent University Pathology Department between the years 2007-2009, and to analyze the immunohistochemical features of p16, p53 and $\mathrm{Ki}-67$ expression and to compare the histopathologic features of the cases with accompanying other vulvar lesions.

\section{Methods}

In this study, all available preparations and paraffin blocks belonging to radical and skinning vulvectomy materials of 18 cases were retrieved from the surgical pathology files of Baskent University Ankara Hospital. All 18 cases of ISSCV and VIN had been operated from January 2007 through June 2009 at Baskent University Ankara Hospital, by the Gynecological Oncology team. Institutional Board Ethical approval for the study was obtained.

Hematoxylin and eosin (H\&E) stained sections for all 18 cases are present. Vulvar squamous cell carcinomas have been grouped into 3 histopathologic types as basaloid, warty and keratinizing, and VINs were evaluated according to 2004 ISSVD terminology (6). The latter were classified as differentiated VIN and classical-usual VIN (which were previously classified as VIN II and VIN III).

Pathology reports were reviewed to obtain the ages of the patients and the localization of tumors. In addition, for the invasive carcinomas, the widest horizontal diameter of the tumor, tumor thickness, the depth of invasion, lymphovascular invasion, lymph node involvement, accompanying cervical or vaginal lesions and vulvar benign lesions were re-evaluated.

Immunohistochemical stains for the paraffin block sections were prepared using p16 (clon $\mathrm{E} 6 \mathrm{H} 4$, mouse monoclonal, CINtec), Ki-67 (MIB-1 clone, rabbit policlonal, Neomarkers) and p53 (DO-7 clone, mouse monoclonal, Neomarkers) antibodies using peroxidase-antiperoxidase method. Strong nuclear and cytoplasmic staining was evaluated positive reaction for $p 16$ expression. p16 reaction pattern was scored semiquantitavely as fallows; negative (-) when less than $1 \%$ of cells were positive, $1+$ : positive reaction in 1-10\% cells, $2+$ : positive reaction in $11-50 \%$ cells, $3+$ : when more than $50 \%$ of cells were positive. Immunostaining for p53, which was always only nuclear, was graded using the same scoring system. The total of 1000 cells in the areas where Ki-67 positive cells peaked, was measured as proliferation index (PI).

\section{Results \\ Histologic features}

Table 1. Clinicopathological features

\begin{tabular}{|c|c|c|c|c|c|c|c|c|}
\hline \multicolumn{5}{|c|}{$\begin{array}{l}\text { Previous } \\
\text { lesion }\end{array}$} & \multicolumn{2}{|c|}{$\begin{array}{c}\text { Non- } \\
\text { neoplastic } \\
\text { lesion }\end{array}$} & \multicolumn{2}{|c|}{$\begin{array}{l}\text { Additional } \\
\text { lesions }\end{array}$} \\
\hline $\begin{array}{c}\text { Case } \\
\text { num- } \\
\text { ber }\end{array}$ & Age & VIN3 & ISCC & $\begin{array}{l}\text { Operation } \\
\text { procedure }\end{array}$ & SCH & LS & $\begin{array}{l}\text { Va- } \\
\text { gen }\end{array}$ & $\begin{array}{l}\text { Cer- } \\
\text { vix }\end{array}$ \\
\hline 1 & 80 & W & - & SV & - & - & - & - \\
\hline 2 & 26 & W & - & SV & + & - & - & - \\
\hline 3 & 29 & W & - & SV & + & - & - & - \\
\hline 4 & 40 & W & - & SV & - & - & - & - \\
\hline 5 & 50 & B & - & SV & - & - & VAIN & LSIL \\
\hline 6 & 36 & W & - & SV & - & - & - & HSIL \\
\hline 7 & 29 & W & - & SV & - & - & - & - \\
\hline 8 & 56 & $D$ & - & SV & + & + & - & - \\
\hline 9 & 52 & W & - & SV & + & - & - & - \\
\hline 10 & 80 & W & W & DWE & - & - & - & - \\
\hline 11 & 73 & - & $\mathrm{K}$ & $\mathrm{HV}$ & - & - & - & - \\
\hline 12 & 58 & - & K & V & + & + & - & - \\
\hline 13 & 61 & - & K & $\mathrm{HV}$ & - & - & - & - \\
\hline 14 & 56 & D & $\mathrm{MI}$ & RV & - & - & - & - \\
\hline 15 & 64 & - & $\mathrm{K}$ & V & + & - & - & - \\
\hline 16 & 66 & D & K & HV & - & - & - & - \\
\hline 17 & 52 & - & K & V & - & - & - & - \\
\hline 18 & 84 & - & v & RV & + & - & - & - \\
\hline
\end{tabular}

VIN-Vulvar intraepithelial neoplasia, ISCC-Invasive squamous cell carcinoma, W-Warty type, B-Basaloid type, D-Differantiated type, K-Keratinizing type, MI-Microinvasive, VC-Verrucous carcinoma, SV-Skinning vulvectomy, DWE-Deep wide excision, HV-Hemivulvectomy, V-Vulvectomy, RV-Radical vulvectomy, SCH-squamous hyperplasia, LS-lichen sclerosis, VAIN-Vaginal intraepithelial neoplasia, LSIL-Low grade squamous intraepithelial lesion, HSIL-High grade squamous intraepithelial lesion.

Of 18 patients who underwent radical and skinning vulvectomy, 9 had ISCCV (6 keratinized type, 1 warty type, 1 microinvasive, 1 other verrucous carcinoma) and of the other 9 patients with VIN. Table 1 shows the clinicopathologic features of the patients.

\section{Association with other conditions}

Together with VIN lesions observed also in invasive carcinoma cases, 3 of the total 12 VIN lesions were classified as differentiated, 1 as basaloid, and 8 as warty types.

$\mathrm{SCH}$ areas were also present in 4 patients with VIN and 3 patients with ISCCV. LS was present in 1 case with keratinizing type invasive carcinoma and 1 case with differentiated VIN.

\section{Immunohistochemical features}

Ki-67 PI: In a total of 9 HPV related VIN cases (8 warty, 1 basaloid), the mean Ki-67 PI was 32,3\%, whereas this value was $26,4 \%$ in 3 differentiated VIN cases.

In keratinizing type invasive carcinoma, the mean Ki-67 proliferation index was $16,75 \%$, and those of one warty and one microinvasive carcinoma case were $20 \%$ and $10,8 \%$, respectively. 


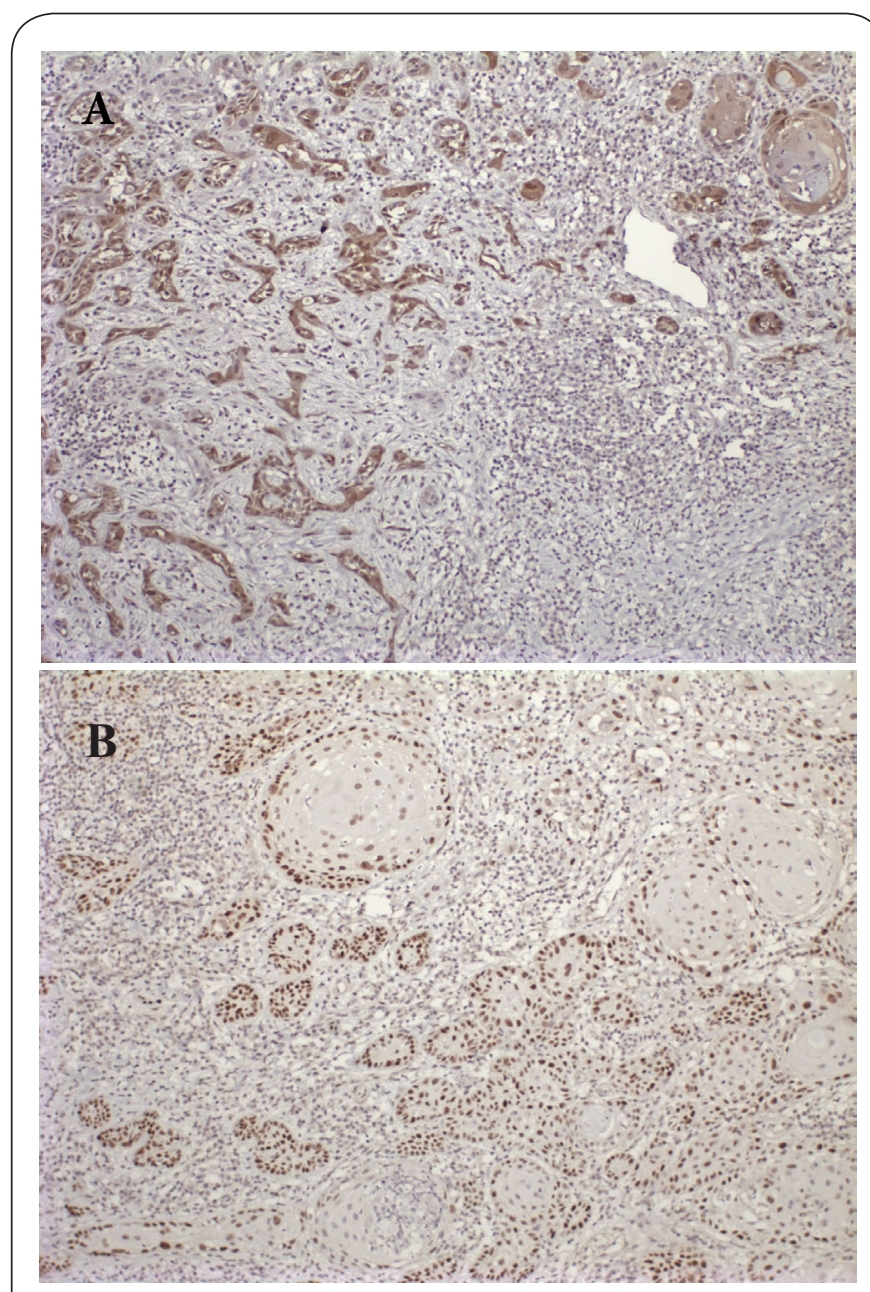

Figure 1a. Strong p16 expression was detected in carcinoma of keratinizing type without the accompanying of HPV-related VIN, 1b. and high p53 expression was observed in the same case, immunoperoxidase $\mathrm{x} 100$.

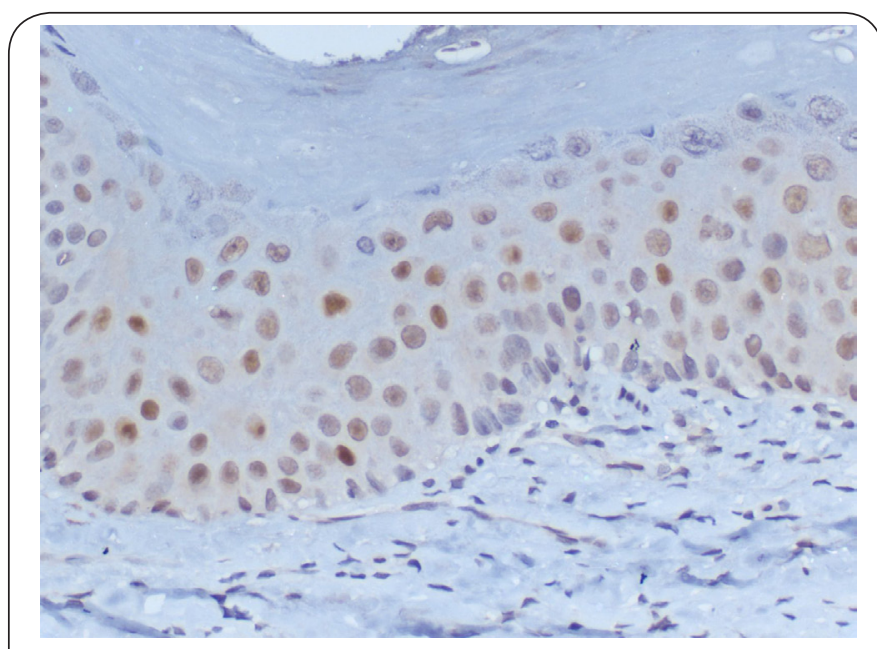

Figure 2. p53 expression was observed in differentiated VIN area in carcinoma of keratinizing type, immunoperoxidase $x 400$.
Table 2. p16 expression pattern, clinical features and followup information invasive carcinoma patients.

\begin{tabular}{|c|c|c|c|c|}
\hline & $1+$ & $2+$ & $3+$ & $4+$ \\
\hline Total & 2 & 1 & 2 & 3 \\
\hline Age & 54 & 64 & 62 & 71,3 \\
\hline \multicolumn{5}{|l|}{ Ki-67 PI } \\
\hline$\leq \% 30$ & 2 & 1 & 2 & 3 \\
\hline$>\% 30$ & - & - & - & - \\
\hline Local recurrency & 0 & 0 & 0 & 0 \\
\hline \multicolumn{5}{|l|}{ Metatasic disease } \\
\hline Lymph node & 0 & 1 & 1 & 1 \\
\hline Distant & 0 & 0 & 1 & 0 \\
\hline \multicolumn{5}{|l|}{ Stage } \\
\hline $1 A$ & - & - & - & 1 \\
\hline $1 B$ & 2 & - & 1 & 1 \\
\hline 2 & - & - & - & - \\
\hline 3 & - & 1 & 1 & 1 \\
\hline 4 & - & - & - & - \\
\hline
\end{tabular}

Table 3: p53 expression pattern, clinical features and followup information invasive carcinoma patients.

\begin{tabular}{|c|c|c|c|c|}
\hline & $1+$ & $2+$ & $3+$ & $4+$ \\
\hline Total & 1 & 1 & 2 & 4 \\
\hline Age & 56 & 80 & 56,5 & 65,25 \\
\hline \multicolumn{5}{|l|}{ Ki-67 PI } \\
\hline$\leq \% 30$ & 1 & 1 & 2 & 4 \\
\hline$>\% 30$ & - & - & - & - \\
\hline Local recurrency & 0 & 0 & 0 & 0 \\
\hline \multicolumn{5}{|l|}{ Metastatic disease } \\
\hline Lymph node & 0 & 0 & 1 & 2 \\
\hline Distant & 0 & 0 & 0 & 1 \\
\hline \multicolumn{5}{|l|}{ Clinical Stage } \\
\hline $1 A$ & - & 1 & - & - \\
\hline $1 B$ & 1 & - & 1 & 2 \\
\hline 2 & - & - & - & - \\
\hline 3 & - & - & 1 & 2 \\
\hline 4 & - & - & - & - \\
\hline
\end{tabular}

Ki-67 proliferation index had a mean $8,07 \%$ in $\mathrm{SCH}$ accompanying the lesions. Ki- 67 proliferation was found to be $8 \%$ and $7 \%$ in two cases with LS.

P16: 16 staining degree had a mean of 2,6 for warty and basaloid type VINs. No p16 expression was detected in differentiated type VINs. Strong p16 expression was detected in 3 carcinomas of keratinizing type (Figure 1a). No p16 immunoreactivity were present in benign vulvar lesions.

P53: P53 expression were observed as $4+$ in 4 cases with ISCCV, as 3+ in cases, 2+ in cases, 1+ in cases (Figure 1b). Tables 2 and 3 summarize the $p 16$ and p53 expression patterns together with clinical and observational information. When evaluated semiquantatively, p53 expression in usual type VINs had a mean of 1,2 and it was 1,6 in differentiated VINs 

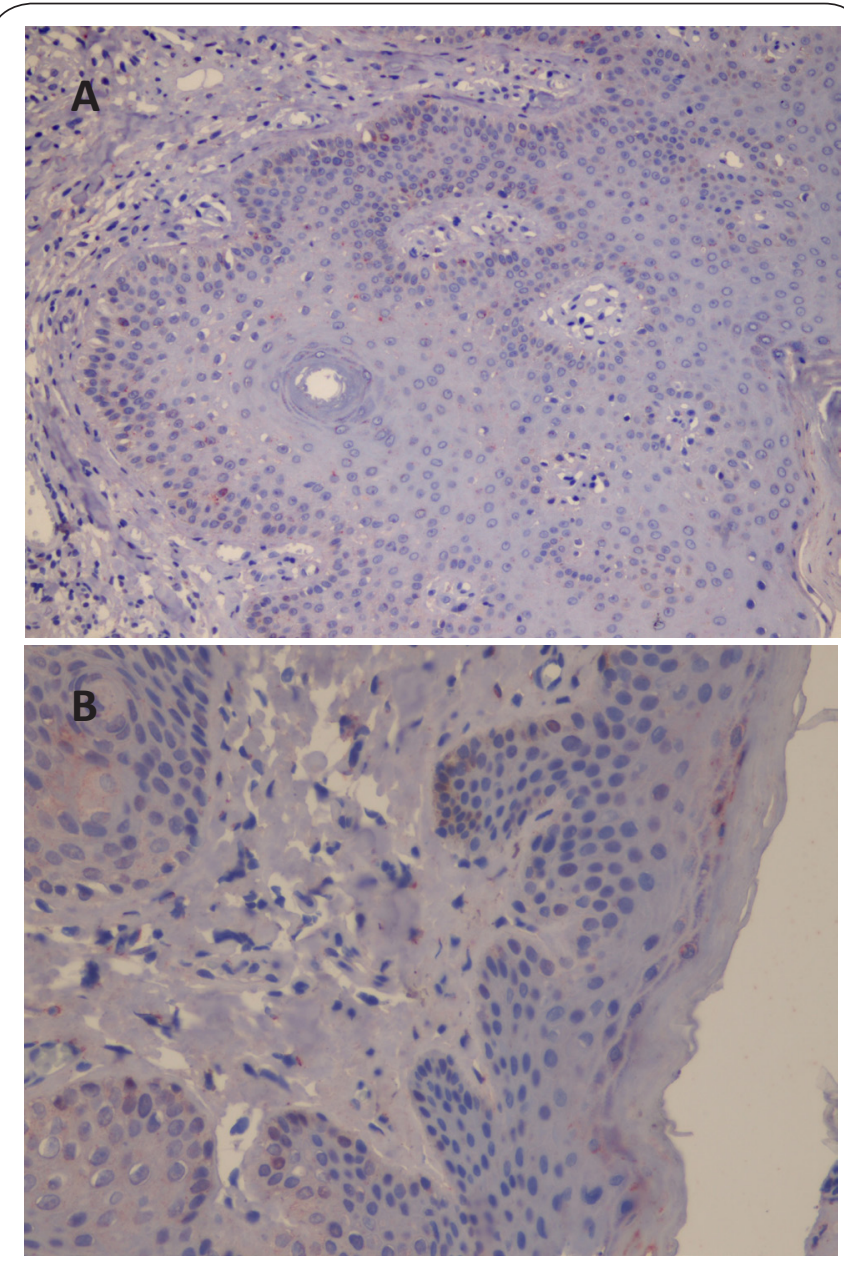

Figure 3a. No p53 expression was present in squamous hiperplasia, immunoperoxidase $\mathrm{x} 100,3 \mathbf{b}$. No p53 expression was present in another case with squamous hiperplasia, immunoperoxidase $\mathrm{x} 200$.

(Figure 2). No p53 immunoreactivity were present in benign vulvar lesions (Figure 3a,3b).

\section{Discussion}

VIN classification has been reviewed after the determination of HPV role in VINs. Haefner et al., observed HPV DNA in 78\% of 58 classic VIN lesions and 14\% of differentiated VINs [13]. Contrary to the studies performed by Haefner et al., many studies using molecular techniques have shown no HPV DNA in vulvar invasive carcinomas $[4,14]$. While warty and basaloid VINs are easily defined because of histopathologic features and immunohistochemical p16 positivity, it is difficult to diagnose differentiated VIN because it can be confused with some benign lesions such as $\mathrm{SCH}[\mathbf{5}, \mathbf{1 2}]$. Therefore, the number of cases with warty and basaloid VIN diagnosis is more than the ones with differentiated type VIN. For this reason, to decrease the mortality rate and its frequency, immunohistochemical staining of Ki-67 and p53 has gained importance to recognize preinvasive vulvar lesions earlier. While $\mathrm{Ki}-67 \mathrm{PI}$ is determined in full thickness of epithelium and diffusely in VIN cases of warty and basaloid characteristics, it has no diagnostic value in differentiated VIN cases. However, it has been stated that increased p53 expression can be used to discriminate the differentiated VIN from other benign lesions $[1,3,12,15]$. Our study supports some studies showing the presence of p53 expression in differentiated VIN and keratinizing type ISCCS accompanied by differentiated VIN. Similar to the cases in literature, no p16 expression was detected in these cases $[\mathbf{2}, \mathbf{1 4}, \mathbf{1 6}]$. On the other hand, in 3 cases with keratinizing type carcinoma showing strong p16 immunoreactivity and not accompanied by usual type VIN, diffuse p53 expression was found. According to these results, p53 expression can be seen in both usual and differantiated VIN and invasive carcinoma cases, and because there was no evidence of p53 expression in SCH or LS lesions observed in our cases, p53 staining can be of reliable utility in distinguishing benign lesions from the malign ones. It has been observed that Ki-67 PI can be found in almost similar ratios in lesions associated with HPV and irrelevant with HPV. However, it has been noted that in strong p53 positivity, Ki-67 PI is also strongly positive.

In contrast to many studies stating that keratizing type invasive carcinomas have no association with HPV, in the present study, strong p16 positivity was detected in 3 ISCCS which were morphologically keratinizing type $[3,4]$. Al-Ghamdi et al., similar to our results, have found in their series of 21 cases that 18 of the invasive carcinomas associated with HPV were of keratinizing type in young patients [1]. The reason for this may be that there is a significant degree of subjectivity in subclassifying invasive vulvar carcinomas and that most of the cases show evidence of keratinization.

Verrucous carcinoma is a discrete variant of ISCC and there is no clear evidence of association with HPV. However, in their series of 10 cases with verrucous carcinoma, Gaulco et al., found that all the cases were found to be HPV negative in in-situ DNA hybridization analysis performed by HPV 6/11, $16 / 18,31 / 35 / 51$ probes [17]. In addition, Santos et al., supported the study of Gaulco et al., by their studies stating that p53 was negative in all the verrucous carcinoma cases $[11,17]$. In our study, in contrast to the studies mentioned above, p53 showed low grade positivity (1+), but in accordance with the cases in literature, $\mathrm{Ki}-67$ proliferation index was rather low (6\%) and p16 was negative.

\section{Conclusions}

ISCCVs are divided into two groups; one associated with HPV and the other not associated with HPV, and it is difficult to subclassify invasive carcinomas into warty, basaloid or keratinizing types depending on morphological features because some of the cases showing strong p16 expression also show evidence of strong keratinization. Although Ki-67 proliferation index does not have significant value in 
Demiralay et al. Journal of Cancer Therapeutics \& Research 2012,

http://www.hoajonline.com/journals/pdf/2049-7962-1-24.pdf

recognizing VIN, p53 positivity can be of value in distinguishing especially differentiated type VIN from benign lesions.

Competing interests

The authors declare that they have no competing interests.

Publication history

Senior Editor: Jiaoti Huang, David Geffen

School of Medicine at UCLA, USA.

EIC: G.J. Peters, VU University Medical Center, Netherlands.

Received: 03-Aug-2012 Revised: 16-Aug-2012

Accepted: 17-Aug-2012 Published: 27-Aug-2012

\section{References}

1. Al-Ghamdi A, Freedman D, Miller D, Poh C, Rosin M, Zhang L, et al.: Vulvar squamous cell carcinoma in young women: a clinicopathologic study of 21 cases. Gynecol Oncol 2002, 84(1):94-101. | Article | PubMed

2. Santos M, Landolfi S, Olivella A, Lloveras B, Klaustermeier J, Suarez H, et al.: p16 overexpression identifies HPV-positive vulvar squamous cell carcinomas. Am J Surg Pathol 2006, 30(11):1347-56. | Article | PubMed

3. Kurman RJ, Toki T, Schiffman MH: Basaloid and warty carcinomas of the vulva. Distinctive types of squamous cell carcinoma frequently associated with human papillomaviruses. Am J Surg Pathol 1993, 17(2):133-45. I PubMed

4. Chiesa-Vottero A, Dvoretsky PM, Hart WR: Histopathologic study of thin vulvar squamous cell carcinomas and associated cutaneous lesions: a correlative study of $\mathbf{4 8}$ tumors in $\mathbf{4 4}$ patients with analysis of adjacent vulvar intraepithelial neoplasia types and lichen sclerosus. Am J Surg Pathol 2006, 30(3):310-8. | Article | PubMed

5. Preti M, Van Seters $M$, Sideri M, Van Beurden M: Squamous vulvar intraepithelial neoplasia. Clin Obstet Gynecol 2005, 48(4):845-61. I Article I PubMed

6. Heller DS: Report of a new ISSVD classification of VIN. J Low Genit Tract Dis 2007, 11(1):46-7. | Article | PubMed

7. Santegoets LA, Seters M, Helmerhorst TJ, Heijmans-Antonissen C, Hanifi-Moghaddam P, Ewing PC, et al.: HPV related VIN: highly proliferative and diminished responsiveness to extracellular signals. Int $J$ Cancer 2007, 121(4):759-66. | Article | PubMed

8. Scurry J, Campion M, Scurry B, Kim SN, Hacker N: Pathologic audit of 164 consecutive cases of vulvar intraepithelial neoplasia. Int J Gynecol Pathol 2006, 25(2):176-81. | Article | PubMed

9. van der Avoort IA, van der Laak JA, Paffen A, Grefte JM, Massuger LF, de Wilde PC, et al.: MIB1 expression in basal cell layer: a diagnostic tool to identify premalignancies of the vulva. Mod Pathol 2007, 20(7):770-8. | Article | PubMed

10. Sideri M, Jones RW, Wilkinson EJ, Preti M, Heller DS, Scurry J, et al.: Squamous vulvar intraepithelial neoplasia: 2004 modified terminology, ISSVD Vulvar Oncology Subcommittee. J Reprod Med 2005, 50(11):807-10. | PubMed

11. Santos M, Montagut C, Mellado B, Garcia A, Ramon y Cajal S, Cardesa $A$, et al.: Immunohistochemical staining for p16 and p53 in premalignant and malignant epithelial lesions of the vulva. Int J Gynecol Pathol 2004, 23(3):206-14. | Article | PubMed

12. Hart WR: Simplex (differantiated) VIN: an underappreciated threat. Ob/Gyn Apr. 1, 2003; 48: 59-83.

13. Haefner HK, Tate JE, McLachlin CM, Crum CP: Vulvar intraepithelial neoplasia: age, morphological phenotype, papillomavirus DNA, and coexisting invasive carcinoma. Hum Pathol 1995, 26(2):147-54. | Article I PubMed

14. Ordi J, Alejo M, Fuste V, Lloveras B, Del Pino M, Alonso I, et al.: HPVnegative vulvar intraepithelial neoplasia (VIN) with basaloid histologic pattern: an unrecognized variant of simplex (differentiated) VIN.
Am J Surg Pathol 2009, 33(11):1659-65. | Article | PubMed

15. Yang B, Hart WR: Vulvar Intraepithelial Neoplasia of the Simplex (Differentiated) Type: A Clinicopathologic Study Including Analysis of HPV and p53 Expression. The American Journal of Surgical Pathology 2000, 24(3). | Article

16. van de Nieuwenhof HP, van Kempen LC, de Hullu JA, Bekkers RL, Bulten J, Melchers WJ, et al.: The etiologic role of HPV in vulvar squamous cell carcinoma fine tuned. Cancer Epidemiol Biomarkers Prev 2009, 18(7):2061-7. | Article | PubMed

17. Gualco $M$, Bonin S, Foglia G, Fulcheri E, Odicino F, Prefumo F, et al.: Morphologic and biologic studies on ten cases of verrucous carcinoma of the vulva supporting the theory of a discrete clinico-pathologic entity. Int J Gynecol Cancer 2003, 13(3):317-24. | Article | PubMed

\section{Citation:}

Demiralay E, Reyhan NH, özen ö, Ksa B, Ayhan $A$ and Demirhan B: Vulvar intraepithelial neoplasia and vulvar squamous cell carcinoma: a clinicopathologic study of 18 cases. journal of Cancer Therapeutics and Research 2012, 1:24. http://dx.doi.org/10.7243/2049-7962-1-24 